\title{
EFETIVIDADE DOS PARCELAMENTOS FISCAIS PARA A SOLVÊNCIA CORPORATIVA NO BRASIL
}

\author{
Sabrina Rafaela Pereira Borges ${ }^{1}$ \\ llírio José Rech²
}

Resumo

Objetivo: A renegociação de dívidas tributárias tem sido justificada sob o enfoque da insolvência, cujo propósito é "salvar" as empresas e recuperar os créditos tributários. Esta pesquisa tem por objetivo verificar a efetividade dos parcelamentos fiscais para a solvência das companhias abertas brasileiras Método: Foram comparados os Z-scores de insolvência de 140 companhias abertas que aderiram ao Programa Especial de Regularização Tributária (PERT) com uma amostra similar de companhias que não fizeram a adesão. Para controlar o efeito de outros fatores utilizou-se o setor de atuação, estado em recuperação judicial e o tamanho das companhias. Para a análise da amostra foram utilizados testes de médias e regressão quantílica nos Z-scores do modelo de Altman (2016).

Resultados: Os testes de médias não foram conclusivos para a análise da efetividade da adesão aos parcelamentos fiscais no nível de insolvência das companhias. Contudo, através do modelo regressivo encontrou-se melhorias dos Z-scores de insolvência das companhias que aderiram ao programa PERT, se diferenciando das demais companhias que não aderiram, dependendo do setor.

Contribuição: Os achados indicam a falta de efetividade dos programas em "salvar" as organizações em dificuldades financeiras. Esses resultados contribuem para chamar a atenção para a necessidade de rever os critérios de adesão aos programas de refinanciamento tributários levando em consideração as necessidades financeiras das companhias. Caso contrário tais mecanismos servem apenas para favorecer os grupos que capturam os governantes, perdendo a efetividade dos programas como auxílio para empresas em dificuldades financeiras.

Palavras-chave: PERT; Insolvência Corporativa; Dívidas Tributárias.

sabrinarpb@yahoo.com.br. Universidade Federal de Uberlândia, Uberlândia-MG. Brasil. https://orcid.org/0000-0002-7110-0784

2ilirio.jose@ufg.br. Universidade Federal de Goiás, Goiânia-GO. Brasil. Brasil. https://orcid.org/0000-0001-7027-737X

- DOI: http://dx.doi.org/10.14392/asaa.2021140103

- Artigo submetido em: 08/10/2020. Revisões requeridas em: 03/02/2021. Aceito em: 17/02/2021. 


\section{INTRODUÇÃO}

$\mathrm{N}$ os momentos de dificuldades financeiras as empresas buscam opções de resolver seus problemas via processos de renegociação de dívidas (Christensen Flor, Lando \& Miltersen, 2014). Em se tratando de dívidas tributárias, as anistias fiscais concedidas via programas de regularização tributária funcionam como uma forma de solucionar os problemas com o fisco. Com isso, as organizações postergam seus pagamentos, e, em alguns casos reduzem os custos de juros e multas, o que pode melhorar a sua condição financeira (Andreoni, 1991).

O elevado número de empresas insolventes e seus efeitos negativos na sociedade têm levado as pesquisas científicas a focar seus estudos na análise dos fatores que levam as empresas ao estado de insolvência (Chung, Tan \& Holdswoth, 2008). Para Bezerra, Lagioia e Pereira (2019), entre os principais fatores que agravam a dificuldade financeira das companhias estão a economia instável, a alta concorrência, o custo elevado do dinheiro e as dívidas tributárias.

De acordo com Dias (2012), o entendimento do papel das dívidas tributárias é relevante para a compreensão do estado de insolvência corporativa, dado o crescimento das dívidas tributárias das organizações. Corrêa (2019) observou que as dívidas das empresas com o governo aumentaram em 84\% de 2013 a 2019, de acordo com dados da Procuradoria-Geral da Fazenda Nacional (PGFN), sendo que os processos judiciais, a morosidade da justiça (decisões duram em média dez anos), a falência e a falta de um patrimônio são as principais justificativas para o não pagamento das dívidas tributárias brasileiras (Takar, 2019).

No estado de insolvência, muitas empresas deixam de efetuar o pagamento dos tributos. Assim, os chamados programas de regularização tributária são vistos com o propósito de "salvar" as empresas e uma possibilidade para a repatriação dos créditos tributários aos cofres públicos pelos contribuintes que estejam insolventes (Somavilla \& Lobato, 2009).

Nesse sentido, a análise da efetividade dos parcelamentos fiscais, no que tange a melhoria do nível de insolvência das empresas que aderiram aos programas de regularização tributária, é relevante para os gestores públicos identificarem situações em que a intervenção do Estado se faça necessária. Além disso, em determinadas situações, a criação de programas de parcelamentos fiscais pode ser a forma de viabilizar o recebimento dos créditos sem comprometer a viabilidade econômico-financeira das empresas.

Tal fator foi destacado pelo Ministro de Estado Henrique de Campos Meirelles na Exposição de Motivos (EM 00060/2017 MF) para apresentação da medida provisória que posteriormente se transformou na Lei no 13.496/2017. De acordo com a Exposição de Motivos, a proposta se justificava pela necessidade de proporcionar às empresas condições para enfrentar a crise econômica e voltar a gerar renda, empregos e pagar seus tributos. Tais justificativas se encaixam nas teorias de regulação dos mercados, mais precisamente na Teoria do Interesse Público (Beaver, 1998).

Todavia, estudos evidenciam que os parcelamentos tributários não são necessários para a recuperação fiscal das empresas e que as mesmas aderem aos programas por questões estratégicas e não por necessidades financeiras (Alm, Mckee \& Beck, 1990; Paes, 2012; Alm, Bruner \& Mckee, 2016). Com base nessa perspectiva há evidencias de que os programas de regularização sejam resultado das pressões de grupos de interesses junto aos governantes, se alinhando ao asseverado pela Teoria da Captura ou Grupo de Interesse (Scott, 2014).

Diante dessas evidências surge o problema de pesquisa a ser investigado: qual a efetividade dos parcelamentos fiscais para a solvência das empresas brasileiras abertas que aderiram aos programas 
especiais de regularização tributária? O objetivo geral deste estudo é verificar a efetividade dos parcelamentos fiscais para a solvência das empresas brasileiras abertas que aderiram aos programas especiais de regularização tributária.

Para alcançar o objetivo foi comparado o Z-score do nível de insolvência de 140 companhias abertas que aderiram ao Programa Especial de Regularização Tributária (PERT) com uma amostra similar de companhias que não fizeram a adesão. Para controlar o efeito de outros fatores utilizou-se como variáveis de controle o setor de atuação, estado em recuperação judicial e o tamanho das companhias. Para calcular os Z-scores se adotou o modelo de Altman, Iwanicz-Drozdowska, Laitinen \& Suvas (2016), pelo fato de ser um modelo reconhecido internacionalmente e aplicável em companhias abertas (Andrade \& Lucena, 2018).

A presente pesquisa contribui por demonstrar a efetividade do parcelamento de dívidas tributárias no que se refere à insolvência das empresas. Analisando a efetividade dos parcelamentos tributários pode-se verificar se o benefício proporcionado pela sociedade cumpre o propósito de "salvar" as empresas em dificuldades financeiras.

Esta pesquisa inova ao analisar as empresas em regularização tributária sob a ótica da insolvência, individualizando as análises sob o prisma de que a adesão aos programas de regularização seria destinada àquelas empresas que precisam melhorar seu estado de solvência, dado o risco de falência. Com isso, a presente pesquisa auxilia os governos nas decisões de políticas, quando do estabelecimento de novos programas de refinanciamento de dívidas tributárias. Além disso, a presente pesquisa auxilia por identificar a necessidade de se preparar para situações em que a adesão aos programas de refinanciamento de dívidas fiscais pode representar uma oportunidade de restabelecer a solvência empresarial.

Este artigo está estruturado em cinco seções, incluindo esta introdução com a contextualização do tema, objetivo e justificativa e contribuição da pesquisa. Em seguida, a segunda seção apresenta a fundamentação teórica acerca da insolvência corporativa e a sua relação com o âmbito das dívidas tributárias. Na terceira seção descreve-se a metodologia da pesquisa, a qual evidencia a amostra de estudo e os métodos de análise utilizados. Na quarta seção, apresentam-se os resultados e as suas análises. Por último, a quinta seção expõe as considerações finais do estudo e suas implicações, bem como as indicações para pesquisas futuras.

\section{REFERENCIAL TEÓRICO}

\subsection{A Insolvência Corporativa}

A insolvência corporativa ocorre quando a empresa não consegue pagar os seus compromissos, uma vez que os seus ativos estão economicamente abaixo dos seus passivos (Guimarães \& Moreira, 2008). Andrade e Lucena (2018) afirmam que a insolvência é vista como um fato econômico próprio do patrimônio que se diferencia da inadimplência. Essa última é caracterizada pela falta de cumprimento de uma dada obrigação, mesmo tendo condições de exercê-la (Guimarães \& Teixeira, 2012). Assim, a insolvência é um estado, enquanto a inadimplência é um ato (Guimarães \& Teixeira, 2012).

O principal enfoque utilizado nos modelos é o uso de indicadores contábeis, obtidos nas demonstrações financeiras, para a previsão de insolvência. A partir da análise de indicadores de empresas que faliram ou passaram por recuperação judicial, os indicadores contábeis são aplicados aos mais variados 
setores econômicos, no sentido de verificar a situação de solvência ou o poder de previsão dos indicadores para o setor.

Entretanto, Altman et al. (2016) destacam a necessidade de atualizar os modelos de insolvência, uma vez que os coeficientes e variáveis perdem a sua capacidade preditiva. As alterações nos cenários macroeconômicos podem afetar a relação entre as variáveis econômico-financeiras com o passar do tempo e reduzir a capacidade dos modelos em prever situações de insolvência.

Nesse sentido, Altman et al. (2016) avaliaram o desempenho do seu modelo Z-score em escala internacional. Para isso, analisaram empresas de 34 países, sendo 31 países europeus. Os achados do estudo foram os mesmos que já haviam sido constatados em estudos preliminares com empresas abertas no final da década de 1960 e, posteriormente, nas empresas privadas em 1983. Destaca-se que os modelos de insolvência desenvolvidos e testados por Altman e outros autores não consideram os efeitos dos tributos nos indicadores.

Por outro lado, embora os tributos não sejam analisados nos modelos, Santos e Machado (2019) verificaram que, normalmente, os planos de recuperação judicial em situações de falência apresentam a possibilidade de pagamento parcelado, perdão e / ou redução da dívida tributária para justificar o pedido de recuperação judicial. Porém, a dúvida que surge é se o "alívio" dessas dívidas melhora a condição que levou a solicitação do pedido de recuperação, na qual as dívidas tributárias são parte de seu estado de insolvência.

\subsection{Os Programas de Regularização Tributária e a Solvência Corporativa}

Os programas de regularização tributária oferecem aos contribuintes inadimplentes a possibilidade de pagarem a totalidade ou parte dos tributos devidos sem estar sujeito a processos e multas (Bayer, Oberhofer \& Winner, 2014).

$\mathrm{Na}$ ótica da insolvência, acredita-se que sem os programas de regularização tributária as empresas não "conseguiriam" pagar as suas dívidas (Takar, 2019). No entanto, ainda não há consenso entre os estudos para a relação entre a situação econômico-financeira das companhias e a adesão aos programas de regularização tributária (Segura, Formigoni \& Grecco, 2012; Ruiz \& Campagnoni, 2019).

Segura et al. (2012) ao avaliarem a situação econômico-financeira das empresas que aderiram ao Refis da Copa, em 2012, concluiu que a adesão ao programa não modifica a rentabilidade, liquidez e o nível de endividamento das empresas. Ruiz e Campagnoni (2019) apresentam que tanto os indicadores econômico-financeiros, quanto o nível de governança também não influenciaram na adesão ao PERT, mas que existem diferenças setoriais significativas, revelando que alguns setores são mais ou menos beneficiados pela adesão ao programa.

Neste aspecto, Horta, Alves e Carvalho (2014) evidenciam que a descontinuidade das empresas do setor de consumo cíclico está associada ao endividamento das companhias, bem como aos aspectos de liquidez e solvência. Já no setor de Materiais Básicos, as empresas são insolventes devido ao nível de endividamento e por conta da dificuldade operacional de gerar caixa (Horta, Borges \& Santos, 2015).

A tributação das empresas influencia nas decisões de estrutura de capital das companhias levando-as a buscar um equilíbrio entre os benefícios fiscais da dívida e os custos da dificuldade financeira (Langedijk Nicodéme, Pagano \& Rossi, 2014). Nesse equilíbrio entre dívidas e benefícios tributários, Carvalho $(2015$, p. 1) revela que "se os executivos tiverem que inadimplir, o governo será a primeira vítima". Assim, mais do que necessidade financeira, a inadimplência tributária, e posterior regularização via adesão aos programas de regularização, pode ser escolhida estrategicamente pelas organizações, sem a real necessidade das empresas por tais fontes de recursos. 


\subsection{Teorias da Regulação como Fundamento para Instituição dos Parcelamentos Fiscais}

Nas áreas de Direito e Economia são diversas as teorias estudadas quando se trata da discussão de regulação de mercado (Beaver, 1998). Entre as diversas teorias da regulação existentes, para esse estudo se destaca a Teoria do Interesse Público e a Teoria da Captura.

Para a Teoria do Interesse Público a regulação é exercida em resposta às demandas publicas na perspectiva de zelar pelo interesse público e evitar externalidades negativas ou monopólios naturais. Do ponto de vista dessa teoria pode-se afirmar que os parcelamentos fiscais são instituídos com o propósito de evitar que as empresas cheguem à falência, o que afetaria o bem estar social (Andreoni, 1991; Christensen et al., 2014; \& Pêgas, 2017). Por isso, quando a economia ou as empresas emitem sinais de dificuldades econômicas ou financeiras, cabe ao Estado, como órgão regulador dos aspectos tributários, intervir para evitar que externalidades negativas e desequilíbrios afetem o funcionamento do mercado.

De acordo com a Teoria da Captura ou Grupo de Interesse, a regulação responde às demandas de grupos interessados em maximizar os lucros de seus membros. Assim, os grupos com poder político ou econômico buscam capturar o regulador para atender aos seus interesses (Scott, 2014). Nesse contexto, sabendo de seu potencial para intervir no poder regulatório, os grupos interessados "aguardam"a criação de programas de anistia fiscal, muitas vezes estimulando contribuintes para a prática de evasão fiscal e a inadimplência tributária, usando de recursos públicos para o financiamento de suas necessidades financeiras (Plutarco, 2012).

Destaca-se que a perspectiva da instituição de novos programas de regularização leva a mais atrasos de pagamento de tributos pelas empresas (Alm, 1998), aumentando os riscos de insolvência. Essa situação pode ser comprovada pelas companhias que aderiram ao primeiro Refis, em 2000. De acordo com Pegas (2017) grande parte das empresas perderam os benefícios do programa por falta de cumprimento dos pagamentos mensais. Isso sustenta a ideia de que o inadimplente tributário tem a tendência de continuar sendo inadimplente (Pêgas, 2017).

Para Marchese \& Cassone (2000), regimes políticos instáveis levam a maior quantidade de anistias fiscais, uma vez que esses estão mais suscetíveis de "serem capturados". Setores com poder político ou econômico exercem pressões nos governantes para a implantação dos parcelamentos fiscais. Essa pressão pôde ser constatada, no Brasil, em 2018, onde o setor do agronegócio obteve o perdão das dívidas dos produtores rurais e das agroindústrias que haviam deixado de pagar o Fundo de Assistência ao Trabalhador Rural (Funrural) (Zala, 2018).

De acordo com os pressupostos da Teoria da Captura, os efeitos da captura dos governantes pelos grupos de interessados afetam o interesse público em prol da maximização do lucro de seus membros. Dessa forma, os programas de anistia fiscal, em sua maioria, ignoram a discussão se, de fato, há necessidade por esse tipo de financiamento público. Somavilla e Lobato (2009) afirmam que os programas de regularização tributária angariam recursos aos cofres públicos que já deveriam ter sido recolhidos. $\mathrm{A}$ falta de recolhimento no prazo devido afeta o bem estar social, prejudicando, inclusive, o planejamento público dos governantes "capturados".

2.4 Hipóteses de Pesquisa

Espera-se que os programas de regularização tributária reduzam os níveis de insolvência. Esses podem ser interpretados como uma ajuda externa ou assistencial de recursos, reduzindo os fluxos de 
pagamentos das empresas, e, consequentemente, melhorando o nível de insolvência (Andreoni, 1991; Neumayer, 2002; Takar, 2019). Diante do exposto, surge a primeira hipótese:

H1: As empresas melhoraram os níveis de insolvência após adesão aos programas de regularização de dívidas tributárias.

Horta et al. (2014) e Horta et al. (2015) evidenciaram que os setores de Consumo Cíclico e Materiais Básicos apresentam comportamentos semelhantes nos níveis de insolvência. Lennox (1989) já havia apresentado que o setor é um dos determinantes para a insolvência de empresas. $\mathrm{O}$ autor considera ainda que a rentabilidade, alavancagem, liquidez e o tamanho da empresa são fatores que afetam o nível de insolvência corporativa. O modelo de previsão de insolvência de Altman et al. (2016) (utilizado nesta pesquisa) considera todos esses fatores em seu modelo, com exceção do setor e tamanho. Logo, espera-se que os níveis de insolvência sejam influenciados pelas peculiaridades setoriais e pelo tamanho das companhias, construindo-se as seguintes hipóteses:

H2: $\mathrm{O}$ setor de atuação das empresas influencia na efetividade dos parcelamentos fiscais para a solvência das empresas brasileiras abertas.

H3: O tamanho das empresas influencia na efetividade dos parcelamentos fiscais para a solvência das empresas brasileiras abertas.

Pereira e Luz (2018) afirmam que na fase de recuperação judicial as empresas preferem deixar de pagar os tributos para posteriormente buscarem os programas de refinanciamentos fiscais, o que pode comprometer ainda mais a sua situação financeira. Dessa forma, a situação de se encontrar em recuperação judicial também pode influenciar nos níveis de insolvência das empresas após a opção de adesão aos parcelamentos fiscais. Logo, surge a seguinte hipótese:

H4: A situação de recuperação judicial influencia na efetividade dos parcelamentos fiscais para a solvência das empresas brasileiras abertas.

\section{ASPECTOS METODOLÓGICOS}

A presente pesquisa é de natureza quantitativa por comparar estatisticamente o Z-score que mede o nível de insolvência de empresas que aderiram ao programa de regularização tributária com as que não aderiram para verificar a efetividade dos parcelamentos fiscais para a solvência das companhias abertas brasileiras. É descritiva por descrever as características das empresas que aderiram ao PERT e seus níveis de insolvência. A pesquisa também pode ser classificada como documental, pois os dados financeiros das empresas foram coletados nas demonstrações financeiras arquivadas no sítio da Brasil, Bolsa, Balcão (B3).

A amostra da pesquisa foi composta por 140 companhias abertas que aderiram ao PERT no período de 2017 e 164 companhias abertas que não aderiram ao programa. Foram coletados dados contábeis das companhias no período de 2015 a 2019, com o objetivo de avaliar os Z-scores de insolvência das empresas dois anos anteriores, no ano da adesão e dois anos posteriores à criação do programa. A análise se desenvolve em um período de curto prazo, visto que a insolvência está mais associada à perda da capacidade de endividamento em um curto espaço de tempo (Horta et al. 2014). 
Quanto à análise e classificação dos Z-scores do nível de insolvência adotou-se como base o Modelo de Altman et al. (2016), inicialmente desenvolvido por Altman (1968), que o amplia para o escopo das companhias abertas. De acordo com o modelo utilizado na pesquisa, o Z-score que mede o estado de insolvência de uma companhia pode ser calculado por meio da Equação 1:

(Equação 1): Z-score = 3,25 +6,56X1 + 3,26X2 + 6,72X3+1,05X4

Conforme a Equação 1, observa-se que 6,56; 3,26; 6,72 e 1,05 envolvem os pesos a serem multiplicados pelos índices. X1 se refere à relação Capital Circulante Líquido (CCL)/ Ativo Total; o X2 é o índice de Reservas de Lucros/Ativo Total; o X3 trata da relação do Lucro Antes de Juros e Impostos (EBIT)/ Ativo Total e X4 representa o Patrimônio Liquido/Exigível Total. A interpretação do Z-score envolve se Z>0 a empresa é solvente e $Z<0$ a empresa é insolvente.

Quanto aos setores, adotou-se como base a classificação da B3 que apresenta os setores classificados em dez grupos. O setor Financeiro foi excluído da amostra diante das particularidades de suas operações e seus efeitos nos dados contábeis que podem afetar os indicadores e enviesar as comparações efetuadas entre os setores. Destaca-se que a categoria "Outros" foi criada para incorporar os setores com menor número de companhias, tais como os setores de Comunicações, Petróleo e Gás e Tecnologia da Informação. Destarte, como variáveis de controle, além do setor, foram incorporadas a variável tamanho e o estado de recuperação judicial das companhias. Para a variável tamanho usou-se o logaritmo natural do ativo total das empresas, segregado em quartis para análise do efeito dessa variável.

Para a comparação entre os Z-scores dos níveis de insolvência das companhias foram aplicados os testes de diferenças de médias, utilizando como suporte os pacotes dos softwares estatísticos Re BioEstat 5.0. Tais testes foram baseados no teste t de Student para amostras independentes via Bootstrap, com o intuito de elevar o poder dos testes realizados através do processo de 3.000 reamostragens.

Por último, foi aplicada a regressão quantílica para aferir a efetividade dos parcelamentos fiscais para a solvência das companhias abertas brasileiras diante da adesão ao programa de regularização tributária, controlando o efeito por setor, tamanho e recuperação judicial. OZ-score que mede o nível de insolvência foi utilizado como variável dependente e as demais variáveis como independentes. Ressalta-se que para o modelo foi adotada uma dummy para a separação entre as empresas que aderiram ou não ao PERT 2017.

A escolha da regressão quantílica se deve ao fato de os Z-scores dos níveis de insolvência serem discrepantes, acarretando em problemas de normalidade e heterogeneidade nos resíduos. A não normalidade pode enviesar os resultados obtidos pela aplicação do método dos mínimos quadrados ordinários. Para superar as limitações do MQO, utiliza-se a regressão quantílica, cujas estimativas são realizadas por meio de quantis com base na mediana, o que garante maior robustez no modelo quando há resíduos com distribuição assimétrica (Koenker, 2005).

Destaca-se ainda que o modelo estimado atendeu aos pressupostos da regressão de independência dos resíduos (teste de Durbin Watson), multicolinearidade (teste Variance Inflation Factor (VIF) $<10$ ) e a endogeneidade (teste de Hausman), todos ao nível de significância de 5\%. A partir dos testes realizados não foram identificadas anomalias. Portanto, por não requerer tratamento de dados específicos, optou-se pela não apresentação dos mesmos. 
As análises foram divididas em três etapas. Primeiramente se buscou analisar o Z-score do nível de insolvência das empresas que fizeram adesão ao PERT e daquelas que não aderiram ao programa. Em seguida, apresenta-se a comparação dos Z-scores de insolvência segregados por setor, tamanho e estado em recuperação judicial, e, por último, o modelo proposto de estimação para o cumprimento dos propósitos específicos deste estudo.

\subsection{Análise da Insolvência}

A Tabela 1 apresenta a distribuição das empresas que aderiram ao PERT 2017, classificadas como solventes e insolventes com base nos Z-scores, distribuídas por setor e ano.

\begin{tabular}{|c|c|c|c|c|c|c|c|c|c|c|}
\hline \multirow{2}{*}{ Tabela 1 - Distribuição das empresas que aderiram ao PERT } \\
\cline { 2 - 15 } & \multicolumn{7}{|c|}{ Empresas Solventes } & \multicolumn{5}{c|}{ Empresas Insolventes } \\
\cline { 2 - 14 } & 2015 & 2016 & 2017 & 2018 & 2019 & 2015 & 2016 & 2017 & 2018 & 2019 \\
\hline Bens Industriais & 27 & 27 & 26 & 27 & 27 & 4 & 4 & 5 & 4 & 5 \\
\hline Consumo Cíclico & 25 & 25 & 24 & 24 & 24 & 4 & 4 & 5 & 5 & 5 \\
\hline Consumo não cíclico & 15 & 16 & 16 & 16 & 14 & 2 & 1 & 1 & 1 & 2 \\
\hline Materiais Básicos & 21 & 20 & 20 & 20 & 20 & 0 & 1 & 1 & 1 & 1 \\
\hline Saúde & 10 & 10 & 10 & 10 & 10 & 0 & 0 & 0 & 0 & 0 \\
\hline Utilidade Pública & 21 & 20 & 20 & 21 & 19 & 1 & 2 & 2 & 1 & 3 \\
\hline Outros & 9 & 9 & 9 & 9 & 9 & 1 & 1 & 1 & 1 & 1 \\
\hline Total & 128 & 127 & 125 & 127 & 123 & 12 & 13 & 15 & 13 & 17 \\
\hline
\end{tabular}

Conforme evidenciado na Tabela 1, no ano de adesão ao PERT, com base nos Z-scores, 125 empresas foram classificadas como solventes e 15 empresas como insolventes. De acordo com Horta et al. (2014) é normal que a quantidade de empresas insolventes seja menor do que as solventes, o que justifica a insolvência apenas em $11 \%$ dos casos analisados.

A Tabela 2 apresenta a distribuição das empresas que não aderiram ao PERT 2017, classificadas como solventes e insolventes com base nos Z-scores, distribuídas por setor e ano.

\begin{tabular}{|c|c|c|c|c|c|c|c|c|c|c|}
\hline \multicolumn{1}{|c|}{ Tabela 2 - Distribuição das empresas que não aderiram ao PERT } \\
\cline { 2 - 15 } Setor & \multicolumn{7}{|c|}{ Empresas Solventes } & \multicolumn{7}{c|}{ Empresas Insolventes } \\
\cline { 2 - 15 } & 2015 & 2016 & 2017 & 2018 & 2019 & 2015 & 2016 & 2017 & 2018 & 2019 \\
\hline Bens Industriais & 43 & 42 & 42 & 39 & 41 & 2 & 3 & 3 & 6 & 4 \\
\hline Consumo Cíclico & 43 & 42 & 41 & 40 & 40 & 2 & 3 & 4 & 5 & 5 \\
\hline Consumo não Cíclico & 7 & 7 & 7 & 7 & 7 & 1 & 1 & 1 & 1 & 1 \\
\hline Materiais Básicos & 8 & 9 & 8 & 7 & 8 & 1 & 0 & 1 & 2 & 1 \\
\hline Saúde & 7 & 7 & 7 & 7 & 7 & 1 & 1 & 1 & 1 & 1 \\
\hline Utilidade Pública & 37 & 37 & 37 & 37 & 37 & 0 & 0 & 0 & 0 & 0 \\
\hline Outros & 10 & 10 & 11 & 10 & 12 & 2 & 2 & 1 & 2 & 0 \\
\hline Total & 155 & 154 & 153 & 147 & 152 & 9 & 10 & 11 & 17 & 12 \\
\hline
\end{tabular}

Por meio das Tabelas 1 e 2 nota-se que o número de empresas solventes e insolventes nos setores de Utilidade Pública, Bens Industriais e Consumo Cíclico estão muito próximos. O menor número de empresas insolventes está no setor de Utilidade Pública (não aderiram) e Saúde (aderiram). Observa-se que o número de empresas insolventes que aderiram ao PERT, em média, é maior que àquelas que 
não aderiram ao programa. Além disso, verifica-se que para as empresas que aderiram ao PERT, houve um crescimento no número de empresas com Z-scores de insolventes em 2017, o que pode derivar do reconhecimento ou reclassificação das dívidas tributárias após a adesão.

As Tabelas 3 e 4 apresentam o resultado da análise dos Z-scores de solvência e insolvência das companhias analisadas que aderiram ao PERT e daquelas que não aderiram.

\begin{tabular}{|c|c|c|c|c|c|c|c|c|c|c|}
\hline & \multicolumn{5}{|c|}{ Z- score de Solvência } & \multicolumn{5}{|c|}{ Z-score de Insolvência } \\
\hline & 2015 & 2016 & 2017 & 2018 & 2019 & 2015 & 2016 & 2017 & 2018 & 2019 \\
\hline Mínimo & 0,85 & 0,67 & 0,47 & 0,44 & 0,52 & $-12,83$ & $-18,69$ & $-27,57$ & $-25,69$ & $-23,58$ \\
\hline Máximo & 19,55 & 19,48 & 51,51 & 20,43 & 22,22 & $-0,14$ & $-0,04$ & $-0,07$ & $-0,52$ & $-0,29$ \\
\hline Mediana & 5,27 & 5,23 & 5,14 & 5,34 & 5,31 & $-1,73$ & $-2,14$ & $-2,95$ & $-4,42$ & $-4,92$ \\
\hline Média Z & 5,26 & 5,26 & 6,02 & 5,67 & 5,69 & $-4,41$ & $-4,79$ & $-6,14$ & $-6,94$ & $-7,64$ \\
\hline \multicolumn{11}{|c|}{ Z-scores das empresas que não aderiram ao PERT } \\
\hline & \multicolumn{5}{|c|}{ Z- score de Solvência } & \multicolumn{5}{|c|}{ Z-score de Insolvência } \\
\hline & 2015 & 2016 & 2017 & 2018 & 2019 & 2015 & 2016 & 2017 & 2018 & 2019 \\
\hline Mínimo & 1,21 & 1,19 & 0,14 & 1,52 & 0,17 & $-43,98$ & $-20,06$ & $-33,30$ & $-297,65$ & $-44,48$ \\
\hline Máximo & 30,93 & 25,10 & 47,02 & 27,83 & 31,29 & $-0,35$ & $-2,91$ & $-0,20$ & $-0,14$ & $-0,82$ \\
\hline Mediana & 5,62 & 5,50 & 5,55 & 5,68 & 5,24 & $-3,57$ & $-6,46$ & $-9,56$ & $-5,48$ & $-7,50$ \\
\hline Média Z & 6,25 & 6,14 & 6,40 & 6,64 & 6,23 & $-9,82$ & $-8,43$ & $-10,90$ & $-25,08$ & $-10,80$ \\
\hline
\end{tabular}

Fonte: Elaboração Própria (2020).

Com base na Tabela 3 se observa que as empresas que aderiram ao PERT mantêm a média dos Z-scores dos níveis de solvência, o que sugere que o programa não teria nenhuma relação com o score de solvência das companhias. Porém, os Z-scores daquelas classificadas como insolventes aumenta a partir do ano de adesão ao programa. De modo preliminar, o resultado sugere que o programa em questão tende a desfavorecer as empresas insolventes.

Tal situação poderia ser agravada se considerar que, após a renegociação das dívidas tributárias, os passivos devem ser classificados de acordo com o vencimento pactuado e reconhecidos a valor justo com base na taxa de juros estabelecida. Isso, em tese, reduz as dívidas tributárias e sua reclassificação pode afetar os indicadores de curto prazo das empresas.

Por parte das empresas que não aderiram ao PERT verifica-se que a média dos Z-scores das empresas solventes se mantêm ao longo do período analisado. Já com base na análise descritiva da média nota-se que os níveis de insolvência das empresas que não aderiram ao programa são superiores aqueles encontrados para as empresas que aderiram ao PERT.

Para verificar o comportamento dos Z-scores antes e após o ano de adesão ao PERT efetuou-se comparações estatísticas dos Z-scores de solvência e insolvência nos períodos anteriores e posteriores a adesão ao programa. Para isso foi aplicado o teste de média t de Student para amostras independentes. As Tabelas 5 apresenta uma síntese dos resultados obtidos.

\section{Tabela 5 - Teste t de Student períodos pré e pós-PERT}

\begin{tabular}{|c|c|c|c|}
\hline & $\mathrm{p}$-valor & Média Antes & Média Após \\
\hline Empresas Solventes & 0,2513 & 5,37 & 5,77 \\
\hline Empresas Insolventes & 0,2190 & $-2,35$ & $-5,07$ \\
\hline
\end{tabular}

Fonte: Elaboração Própria (2020). 
De acordo com a Tabela 5 destaca-se que apesar de o Z-score médio de solvência e insolvência aumentar visivelmente nas empresas que aderiram ao PERT, não houve diferenças estatísticas significativas ao nível de confiança de $95 \%$ antes e após a adesão das empresas ao programa. Esses achados implicam na expectativa de que a adesão aos programas de regularização de dívidas tributárias não influencia, estatisticamente, no nível de insolvência das empresas, o que rejeitaria a hipótese $\mathrm{H} 1$ da pesquisa.

A tabela 6 visa comparar os dados de solvência e insolvência antes e após a adesão aos programas de recuperação fiscal, segregados por melhora, manutenção e piora do Z-score.

\begin{tabular}{|c|c|c|}
\multicolumn{1}{|c}{ Tabela 6 - Comparação das empresas pré e pós adesão } \\
\begin{tabular}{|c|c|c|}
\hline Solvência & Quantidade & $\%$ \\
\hline Empresas que melhoraram Z-score & 74 & 60,65 \\
\hline Empresas que pioraram Z-score & 44 & 36,07 \\
\hline Empresas que mantiveram Z-score & 4 & 3,28 \\
\hline Total & 122 & 100 \\
\hline Insolvência & Quantidade & $\%$ \\
\hline Empresas que melhoraram Z-score & 7 & 38,88 \\
\hline Empresas que pioraram Z-score & 11 & 61,12 \\
\hline Empresas que mantiveram Z-score & 0 & 0,00 \\
\hline Total & 18 & 100 \\
\hline
\end{tabular}
\end{tabular}

Fonte: Elaboração Própria (2020).

Observa-se que $60,65 \%$ das companhias solventes aumentaram o Z-score após a adesão ao PERT, enquanto que $36,07 \%$ pioraram. Tais evidências sugerem que as empresas aderem aos programas de regularização tributária por questões estratégicas e não por necessidades financeiras, o que corrobora com os achados de Alm, Mckee e Beck (1990); Paes (2012) e Alm, Bruner e Mckee (2016); e contradizem as afirmações de Takar (2019) para a viabilidade dos programas em termos de recuperação financeira das companhias.

Por outro lado, $61,12 \%$ das empresas classificadas como insolventes pioraram seu Z-score demonstrando que a adesão aos PERT, para essas empresas, piora seus indicadores. Tais resultados corrobora a percepção de que há uma transferência de recursos públicos para empresas que, aparentemente não necessitavam dos parcelamentos para sua solvência.

\subsection{Análise das Características das Empresas}

Com a finalidade de verificar se os resultados acima encontrados diferem a partir das características das empresas, as análises a seguir confrontam o comportamento das companhias que aderiram ao PERT conforme o tamanho e a situação de recuperação judicial.

A Tabela 7 apresenta os resultados segregados pelas empresas que aderiram e não aderiram ao programa de acordo as duas características. 
Tabela 7 - Comparação dos Z-scores com base no tamanho e recuperação judicial em quartis

\begin{tabular}{|c|c|c|c|c|c|c|c|c|c|}
\hline & & \multicolumn{4}{|c|}{ Aderiram ao PERT } & \multicolumn{4}{|c|}{ Não Aderiram ao PERT } \\
\hline & & \multicolumn{2}{|c|}{ Solventes } & \multicolumn{2}{|c|}{ Insolventes } & \multicolumn{2}{|c|}{ Solventes } & \multicolumn{2}{|c|}{ Insolventes } \\
\hline \multirow{6}{*}{ Tamanho } & Quartil & $n^{\circ}$ & $\%$ & $\mathrm{n}^{\circ}$ & $\%$ & $n^{\circ}$ & $\%$ & $n^{\circ}$ & $\%$ \\
\hline & $1^{\circ}$ & 22 & $18 \%$ & 12 & $67 \%$ & 34 & $23 \%$ & 7 & $37 \%$ \\
\hline & $2^{\circ}$ & 31 & $25 \%$ & 5 & $28 \%$ & 32 & $22 \%$ & 7 & $37 \%$ \\
\hline & $3^{\circ}$ & 35 & $29 \%$ & 1 & $6 \%$ & 39 & $27 \%$ & 4 & $21 \%$ \\
\hline & $4^{\circ}$ & 34 & $28 \%$ & 0 & 0 & 40 & $28 \%$ & 1 & $5 \%$ \\
\hline & Total & 122 & $100 \%$ & 18 & $100 \%$ & 145 & $100 \%$ & 19 & $100 \%$ \\
\hline \multirow{3}{*}{ Recuperação Judicial } & Sim & 9 & $2 \%$ & 9 & $50 \%$ & 2 & $1 \%$ & 8 & $42 \%$ \\
\hline & Não & 113 & $117 \%$ & 9 & $50 \%$ & 143 & $99 \%$ & 11 & $58 \%$ \\
\hline & Total & 122 & $100 \%$ & 18 & $100 \%$ & 145 & $100 \%$ & 19 & $100 \%$ \\
\hline
\end{tabular}

Fonte: Elaboração Própria (2020).

De acordo com a Tabela 7, se observa que $67 \%$ das companhias que aderiram ao PERT e estão insolventes são empresas classificadas no $1^{\circ}$ quartil da amostra, o que sugere uma possível relação entre o tamanho das empresas e os níveis de insolvência das companhias que aderem aos programas de regularização de dívidas tributárias. Destarte, destaca-se que 18 (12,86\%) companhias que aderiram ao PERT estiveram ou ainda estão em processos de recuperação judicial, das quais $50 \%$ estão em estado de insolvência.

Outra característica destacada na literatura que influencia a adesão a programas de renegociação de dívidas e os níveis de insolvência é o setor de atuação das empresas (Lennox, 1989; Horta et al. 2014; Horta et al. 2015).

A Tabela 8 apresenta uma síntese dos Z-scores setoriais das companhias solventes.

Tabela 8 - Média Z-score das empresas solventes por setor

\begin{tabular}{|c|c|c|c|c|c|c|c|c|c|}
\hline \multirow{2}{*}{ Setor } & \multirow{2}{*}{ Adesão } & \multicolumn{8}{|c|}{ Média Z-score } \\
\hline & & 2015 & 2016 & 2017 & 2018 & 2019 & Desvio & Média & $\mathrm{p}$-valor \\
\hline \multirow{2}{*}{ UTI } & s & 4,77 & 4,88 & 4,82 & 4,77 & 5,10 & \multirow{2}{*}{1,3460} & \multirow{2}{*}{5,5410} & \multirow{2}{*}{$0,0013^{* *}$} \\
\hline & $\mathrm{N}$ & 6,18 & 6,04 & 5,68 & 6,52 & 6,65 & & & \\
\hline \multirow{2}{*}{ SAUD } & $\mathrm{s}$ & 6,84 & 6,53 & 6,49 & 7,07 & 6,40 & \multirow{2}{*}{0,1580} & \multirow{2}{*}{6,7450} & \multirow{2}{*}{0,4907} \\
\hline & $\mathrm{N}$ & 7,25 & 6,11 & 6,69 & 7,34 & 6,73 & & & \\
\hline \multirow{2}{*}{ MB } & s & 4,52 & 4,34 & 5,46 & 6,06 & 5,96 & \multirow{2}{*}{2,5780} & \multirow{2}{*}{6,5570} & \multirow{2}{*}{$0,0060^{* *}$} \\
\hline & $\mathrm{N}$ & 7,46 & 7,01 & 8,07 & 9,40 & 7,29 & & & \\
\hline \multirow{2}{*}{ CNC } & s & 5,58 & 5,45 & 5,71 & 5,19 & 5,41 & \multirow{2}{*}{0,5620} & \multirow{2}{*}{5,7490} & \multirow{2}{*}{$0,0120^{* *}$} \\
\hline & $\mathrm{N}$ & 6,43 & 6,13 & 5,71 & 6,21 & 5,67 & & & \\
\hline \multirow{2}{*}{ СC } & s & 6,43 & 6,32 & 7,44 & 6,94 & 6,77 & \multirow{2}{*}{0,0140} & \multirow{2}{*}{6,7730} & \multirow{2}{*}{$0,0557^{*}$} \\
\hline & $\mathrm{N}$ & 6,69 & 6,74 & 6,83 & 6,85 & 6,72 & & & \\
\hline \multirow{2}{*}{$\mathrm{Bl}$} & s & 4,35 & 4,56 & 6,30 & 4,56 & 4,65 & \multirow{2}{*}{0,8680} & \multirow{2}{*}{5,3180} & \multirow{2}{*}{$0,0630^{*}$} \\
\hline & $\mathrm{N}$ & 5,19 & 5,34 & 6,52 & 6,11 & 5,60 & & & \\
\hline \multirow{2}{*}{ OUT } & s & 5,32 & 5,54 & 5,69 & 6,05 & 6,30 & \multirow{2}{*}{0,4340} & \multirow{2}{*}{5,9970} & \multirow{2}{*}{0,3117} \\
\hline & $\mathrm{N}$ & 7,42 & 6,60 & 5,76 & 6,21 & 5,08 & & & \\
\hline
\end{tabular}

UTI= Utilidade Pública; $S A U U D=$ Saúde; $M B=$ Materiais Básicos; $C N C=$ Consumo não Cíclico; $C C=$ Consumo Cíclico; $B I=$ Bens Industriais; OUT= Outros; $S=\operatorname{Sim} ; N=$ Não.

Fonte: Dados da Pesquisa (2020).

Pela Tabela 8 se verifica que os níveis de solvência são estatisticamente diferentes entre as empresas que aderiram daquelas que não aderiram ao PERT para os setores de Utilidade Pública, Consumo não Cíclico e Consumo Cíclico. Destaca-se que o PERT 2017 não faz distinção quanto às características das 
empresas para adesão aos programas. No entanto, a adesão ao PERT pode influenciar o nível de solvência das companhias de modo diferente entre os setores.

Destarte, o nível médio de solvência das empresas que aderiram ao PERT tende a convergir para a média apresentada pelas empresas que não fizeram a adesão ao programa. A exceção ocorreu para o setor de Consumo não Cíclico, no qual nota-se que o nível de solvência das companhias que aderiram ao PERT apresentou um comportamento inverso daquelas que não aderiram.

A Tabela 9 apresenta uma síntese dos resultados encontrados para os setores analisados a partir do teste de média realizado para os Z-scores de insolvência.

Tabela 9 - Média Z-score das empresas insolventes por setor

\begin{tabular}{|c|c|c|c|c|c|c|c|c|c|}
\hline \multirow[b]{2}{*}{ Setor } & \multirow[b]{2}{*}{ Adesão } & \multicolumn{8}{|c|}{ Média Z-score } \\
\hline & & 2015 & 2016 & 2017 & 2018 & 2019 & $\begin{array}{l}\text { Desvio } \\
\text { padrão }\end{array}$ & $\begin{array}{l}\text { Média } \\
\text { geral }\end{array}$ & $\mathrm{p}$-valor \\
\hline \multirow{2}{*}{ UTI } & s & $-1,46$ & $-1,40$ & $-2,69$ & $-4,42$ & $-5,56$ & \multirow{2}{*}{1,8399} & \multirow{2}{*}{$-3,1060$} & \multirow{2}{*}{ - } \\
\hline & $\mathrm{N}$ & - & - & - & - & - & & & \\
\hline \multirow{2}{*}{ SAUD } & s & - & $-16,24$ & - & - & - & \multirow{2}{*}{133,73} & \multirow{2}{*}{$-97,793$} & \multirow{2}{*}{ - } \\
\hline & $\mathrm{N}$ & $-43,98$ & - & $-33,30$ & $-297,65$ & - & & & \\
\hline \multirow{2}{*}{ MB } & $\mathrm{s}$ & - & $-0,61$ & $-0,07$ & $-0,87$ & $-1,96$ & \multirow{2}{*}{20,608} & \multirow{2}{*}{$-11,181$} & \multirow{2}{*}{$0,0390^{* *}$} \\
\hline & $\mathrm{N}$ & $-3,15$ & - & $-18,94$ & $-19,37$ & $-44,48$ & & & \\
\hline \multirow{2}{*}{ CNC } & $S$ & $-0,53$ & $-0,04$ & $-5,10$ & $-10,87$ & $-13,85$ & \multirow{2}{*}{2,7560} & \multirow{2}{*}{$-7,4560$} & \multirow{2}{*}{0,3093} \\
\hline & $\mathrm{N}$ & $-6,32$ & $-7,44$ & $-9,56$ & $-10,78$ & $-10,07$ & & & \\
\hline \multirow{2}{*}{ CC } & $\mathrm{s}$ & $-6,93$ & $-7,52$ & $-8,31$ & $-7,95$ & $-8,81$ & \multirow{2}{*}{1,9620} & \multirow{2}{*}{$-6,9230$} & \multirow{2}{*}{$0,0193^{* *}$} \\
\hline & $\mathrm{N}$ & $-5,76$ & $-7,98$ & $-5,06$ & $-5,61$ & $-5,30$ & & & \\
\hline \multirow{2}{*}{ BI } & $S$ & $-4,07$ & $-2,52$ & $-3,54$ & $-7,10$ & $-8,77$ & \multirow{2}{*}{4,2098} & \multirow{2}{*}{$-7,3049$} & \multirow{2}{*}{$0,0130^{* *}$} \\
\hline & $\mathrm{N}$ & $-9,17$ & $-9,57$ & $-11,34$ & $-7,99$ & $-8,97$ & & & \\
\hline \multirow{2}{*}{ OUT } & s & $-6,49$ & $-18,69$ & $-22,28$ & $-5,94$ & $-4,08$ & \multirow{2}{*}{$-7,7100$} & \multirow{2}{*}{8,5185} & \multirow{2}{*}{$0,0730^{*}$} \\
\hline & $\mathrm{N}$ & $-2,55$ & $-3,98$ & $-3,80$ & $-1,58$ & - & & & \\
\hline
\end{tabular}

UTI= Utilidade Pública; $S A U U D=$ Saúde; $M B=$ Materiais Básicos; $C N C=$ Consumo não Cíclico; $C C=$ Consumo Cíclico; $B I=$ Bens Industriais; OUT= Outros; $S=\operatorname{Sim} ; N=$ Não.

Fonte: Dados da Pesquisa (2020).

Observa-se na Tabela 9 que os níveis de insolvência são estatisticamente diferentes entre as empresas que fizeram a adesão e aquelas que não aderiram ao PERT nos setores de Materiais Básicos, Consumo Cíclico, Bens Industriais e Outros.

Ressalta-se que o ano de adesão tende a piorar o nível de insolvência das empresas que aderiram ao PERT. Apesar dos setores de Consumo Cíclico e Materiais Básicos serem os mais afetados negativamente pela insolvência conforme apresentado por Horta et al. (2014) e Horta et al. (2015), quando as empresas aderem aos parcelamentos fiscais o setor de Saúde se mostrou mais insolvente.

Os resultados permitem sugerir que a adesão ao PERT, além de desfavorecer as empresas em estado de insolvência, como já evidenciado, destaca influências das peculiaridades setoriais, o que dá indícios para a não rejeição da hipótese $\mathrm{H} 2$ da pesquisa de que o setor de atuação das empresas influencia na efetividade dos parcelamentos fiscais para a solvência das empresas brasileiras abertas.

\subsection{Regressão Quantílica e Análise dos Resultados}

Para verificar se as características das empresas, em conjunto, influenciam na efetividade dos parcelamentos fiscais para a solvência das empresas brasileiras abertas se realizou os testes com base na 
regressão quantílica. As análises consideraram a interação entre as variáveis e o critério de seleção de variáveis backward para o modelo. Para evitar a interferência de valores extremos, optou-se pela regressão quantílica com base na mediana. A Tabela 10 apresenta o modelo estimado.

Tabela 10- Regressão Quantílica: Mediana

\begin{tabular}{|c|c|c|c|c|}
\hline Variável & Estimativa & Desvio-padrão & Valor $\mathrm{t}$ & P-valor \\
\hline Intercepto & 5,39 & 0,06983 & 77,18 & $0,0000^{* *}$ \\
\hline Setor Consumo Cíclico & $-0,02$ & 0,07760 & $-0,26$ & 0,7966 \\
\hline Setor Consumo não Cíclico & $-0,09$ & 0,08937 & $-1,01$ & 0,3141 \\
\hline Setor Materiais Básicos & 0,11 & 0,09784 & 1,12 & 0,2611 \\
\hline Setor Outros & $-0,02$ & 0,81391 & $-0,02$ & 0,9804 \\
\hline Setor Saúde & $-0,18$ & 0,10889 & $-1,65$ & 0,0985 \\
\hline Setor Utilidade Pública & $-0,05$ & 0,10104 & $-0,49$ & 0,6208 \\
\hline Tamanho $-2^{\circ}$ Quartil & 0,74 & 0,07239 & 10,22 & $0,0000^{* *}$ \\
\hline Tamanho $-3^{\circ}$ Quartil & 1,27 & 0,08130 & 15,62 & $0,0000^{* *}$ \\
\hline Tamanho $-4^{\circ}$ Quartil & 1,76 & 0,07964 & 22,10 & $0,0000^{* *}$ \\
\hline Recuperação Judicial (Sim) & $-0,15$ & 0,03812 & $-3,94$ & $0,0001^{* *}$ \\
\hline Adesão: Setor Consumo Cíclico & 0,15 & 0,06286 & 2,38 & $0,0171^{*}$ \\
\hline Adesão: Setor Consumo não Cíclico & 0,05 & 0,1430 & 0,35 & 0,7267 \\
\hline Adesão: Setor Materiais Básicos & 0,07 & 0,07126 & 0,98 & 0,3261 \\
\hline Adesão: Setor Outros & 0,39 & 0,54541 & 0,71 & 0,4747 \\
\hline Adesão: Setor Saúde & 0,26 & 0,07615 & 3,41 & $0,0066^{* *}$ \\
\hline Adesão: Setor Utilidade Pública & 0,20 & 0,07319 & 2,73 & $0,0064^{* *}$ \\
\hline Setor Consumo Cíclico: Tamanho $3^{\circ}$ Quartil & 0,03 & 0,08295 & 0,36 & 0,7177 \\
\hline Setor Consumo não Cíclico: Tamanho - $2^{\circ}$ Quartil & 0,09 & 0,12750 & 0,71 & 0,4804 \\
\hline Setor Materiais Básicos: Tamanho- $2^{\circ}$ Quartil & $-0,25$ & 0,13543 & $-1,85$ & 0,0651 \\
\hline Setor Outros: Porte Tamanho- $2^{\circ}$ Quartil & $-0,21$ & 1,07472 & $-0,20$ & 0,8451 \\
\hline Setor Saúde: Porte Tamanho- $2^{\circ}$ Quartil & 0,13 & 0,15652 & 0,83 & 0,4064 \\
\hline Setor Utilidade Pública: Tamanho - $2^{\circ}$ Quartil & $-0,03$ & 0,15699 & $-0,19$ & 0,8485 \\
\hline Setor Consumo Cíclico: Tamanho - $3^{\circ}$ Quartil & $-0,05$ & 0,09320 & $-0,54$ & 0,5917 \\
\hline Setor Consumo não Cíclico: Tamanho - $3^{\circ}$ Quartil & 0,18 & 0,17055 & 1,06 & 0,2914 \\
\hline Setor Materiais Básicos: Tamanho- $3^{\circ}$ Quartil & $-0,25$ & 0,10668 & $-2,34$ & $0,0192^{*}$ \\
\hline Setor Outros: Tamanho $-3^{\circ}$ Quartil & $-0,11$ & 0,81673 & $-0,13$ & 0,8929 \\
\hline Setor Saúde: Tamanho - $3^{\circ}$ Quartil & 0,06 & 0,11792 & 0,51 & 0,6110 \\
\hline Setor Utilidade Pública: Tamanho - $3^{\circ}$ Quartil & $-0,04$ & 0,11422 & $-0,35$ & 0,7262 \\
\hline Setor Consumo Cíclico: Tamanho - $4^{\circ}$ Quartil & $-0,03$ & 0,11224 & $-0,27$ & 0,7893 \\
\hline Setor Consumo não Cíclico: Tamanho - $4^{\circ}$ Quartil & 0,20 & 0,16364 & 1,22 & 0,2218 \\
\hline Setor Materiais Básicos: Tamanho - $4^{\circ}$ Quartil & 0,21 & 0,13285 & 1,58 & 0,1142 \\
\hline Setor Outros: Tamanho - $4^{\circ}$ Quartil & 0,09 & 1,10730 & 0,08 & 0,9352 \\
\hline Setor Saúde: Tamanho - $4^{\circ}$ Quartil & 1,98 & 0,19474 & 10,17 & $0,0000^{* *}$ \\
\hline Setor Utilidade Pública: Tamanho - $4^{\circ}$ Quartil & $-0,08$ & 0,11933 & $-0,67$ & 0,5027 \\
\hline
\end{tabular}

Fonte: Elaboração Própria (2020). *Significativo ao nível de 5\% **Significativo ao nível de $1 \%$.

Os resultados apresentados na Tabela 10 sugerem que o fato de as empresas pertencerem aos setores de Consumo Cíclico, Saúde e Utilidade Pública e aderirem ao PERT influencia positivamente no seu nível de insolvência. Ressalta-se que no período de 2015 a 2017 o Brasil passou por instabilidades políticas e agravamento da crise econômica o que também pode ter influenciado nos resultados encontrados.

Considerando tais limitações, os resultados encontrados na regressão quantílica confirmam a não rejeição da hipótese $\mathrm{H} 2$, confirmando que o setor de atuação influencia na efetividade dos parcelamentos fiscais para a solvência das empresas brasileiras abertas. 
Para Lennox (1989) o tamanho é um fator que impacta positivamente nos indicadores de solvência e insolvência das companhias, principalmente nas empresas de médio e grande porte. Os resultados da regressão quantílica demonstram que essa variável não apresenta efeito significativo sobre o Z-score para empresas classificadas no primeiro quartil da amostra, nem para aquelas que aderiram ao PERT. Logo, há evidências para se rejeitar a hipótese $\mathrm{H} 3$ de que o tamanho das empresas exerce influência na efetividade dos parcelamentos fiscais para a solvência das empresas brasileiras abertas.

As empresas em recuperação judicial apresentam efeitos negativos para a efetividade dos parcelamentos fiscais para a solvência das empresas. Assim sendo, conforme esperado, o fato de a empresa já estar com problemas financeiros reflete em menores níveis de solvência e corrobora com os achados de Pereira e Luz (2018) acerca do comprometimento da situação financeira de empresas que aderem aos parcelamentos fiscais. Porém, não foi encontrada associação significativa entre a recuperação judicial e a adesão ao PERT 2017 conforme o quantil de insolvência, o que revela que o programa não teria o papel de ajudar financeiramente as empresas que estão em maiores dificuldades financeiras. Assim sendo, há evidências para a rejeição da hipótese $\mathrm{H} 4$ de que a situação das empresas em recuperação judicial influencia na efetividade dos parcelamentos fiscais para a solvência das empresas.

Em síntese, os resultados encontrados indicam que há influências positivas dos programas de regularização tributária sobre o Z-score das companhias classificadas como solventes, porém essas dependem, sobretudo, do setor. Desse modo, as organizações solventes dos setores de Consumo Cíclico, Saúde e Utilidade Pública são as que conseguiram melhorias em seus Z-scores de insolvência ao aderirem aos programas de regularização tributária. Por outro lado, a adesão afetou o nível de insolvência nos setores de Materiais Básicos, Consumo Cíclico e Bens Industriais quando as empresas se situam nos níveis considerados em estado de insolvência. Consequentemente, com base nos resultados da regressão infere-se que o setor é um fator que afeta a efetividade dos parcelamentos fiscais para a solvência das empresas.

Alm (2018) destaca a relevância do entendimento dos segmentos de contribuintes e seus comportamentos para a conformidade fiscal. Isso se deve ao fato de o setor ser um dos determinantes para a insolvência corporativa, conforme destacado por Lennox (1989). Além disso, pode ser verificada a influência dos setores na adesão aos parcelamentos, que pode ser explicada pela Teoria da Captura. Dessa forma, as evidências sugerem que determinados setores exercem pressão sobre os governantes para a existência dos parcelamentos fiscais, bem como a constituição de parcelamentos específicos direcionados para tais setores.

No que tange ao tamanho, os achados evidenciam que as maiores corporações (4 quartil da amostra) com melhores condições econômicas são as maiores beneficiadas pelos programas. No entanto, não foi possível considerar a influência da situação de recuperação judicial e do tamanho das companhias na efetividade dos programas de regularização tributária. A falta de significância estatística pode ter sido influenciada pela quantidade de empresas na amostra com Z-score de insolvência.

De um modo geral, os programas não representam ajuda financeira para as empresas em estado de insolvência. Consequentemente, os resultados encontrados refutam a hipótese da efetividade dos parcelamentos fiscais para melhoria da insolvência das empresas brasileiras abertas, levando consequentemente à rejeição da hipótese $\mathrm{H} 1$.

Esse resultado indica que as empresas não aderem à renegociação de dívidas tributárias por necessidade financeira. Considerando que os tributos ingressaram no caixa das empresas, a renegociação 
torna-se uma forma estratégica de manter a capacidade financeira com fontes de recursos de menores exigências creditícias.

A falta de efetividade dos programas de parcelamento na solvência das empresas fortalece os pressupostos da Teoria da Captura de que os governantes são pressionados por grupos interessados na criação de programas de regularização tributária, cuja existência dessa pressão é destacada nos estudos de Marchese e Cassone (2000) e Zala (2018).

\section{CONSIDERAÇÕES FINAIS}

Esta pesquisa teve como propósito verificar a efetividade dos parcelamentos fiscais para a solvência das companhias abertas brasileiras. Por meio de comparação dos Z-scores que mede o nível de insolvência de uma amostra de companhias que aderiram ao PERT, bem como da análise das características das empresas, sugere-se que o PERT 2017 melhorou, de forma significativa, o Z-score das companhias solventes, dependendo do setor.

Por outro lado, as evidencias sugerem que, ao contrário de o que é usado para justificar os programas de parcelamentos tributários, esses não têm efetividade para "salvar" as empresas como alegado nas justificativas de aprovação das leis e a Teoria do Interesse Público. Os achados revelam que os programas de regularização tributária falham na perspectiva de o Estado proteger o bem estar social, uma vez que àquelas empresas em dificuldades financeiras não se beneficiaram do esforço coletivo para manter empregos, renda e serviços. Desta forma, as evidências apresentadas nesse estudo sugerem que outros interesses, que não o interesse público e bem estar social, predomina para a criação de programas de regularização tributaria.

A pressão de grupos de interesse como asseverado pela Teoria da Captura pode ser uma justificativa para a ausência de critérios para adesão aos benefícios de um parcelamento. Considerando que os programas de parcelamentos retêm recursos públicos no caixa das empresas, que, em tese, deveriam ser destinados a interesses públicos, os parcelamentos tributários deveriam ser baseados em critérios de necessidades e prioridades. No entanto não se verifica tais discussões nos parcelamentos instituídos pelo PERT 2017, demonstrando evidências da captura dos governantes pelos grupos de interesse em maximizar os seus lucros.

Em termos econômicos, as evidências encontradas sugerem que os programas estão sendo utilizados estrategicamente pelas companhias para outros fins, tais como reduzir suas despesas de juros ou melhorar o acesso ao crédito, sem passar pelas exigências imposta pelo mercado de crédito, uma vez que o PERT não impõe quaisquer critérios financeiros para adesão.

Diante do exposto, os programas de renegociação de dívidas se tornam uma fonte de financiamento barata e de baixo enforcement para sua adimplência pelas empresas, afetando o nível de receitas do Estado. Contudo, as condições estabelecidas nos programas de regularização tributária fazem com que esses sirvam de transferência de recursos para os grupos de interesse, conforme defendido pela Teoria da Captura. A falta de efetividade dos programas de parcelamento para melhorar a solvência das empresas verificada na presente pesquisa, sugere que os programas se transformam em formas de financiamentos para grupos privados. 
Além da falta de efetividade dos programas, os grupos de interesse também exercem pressões para que as informações não sejam levadas ao conhecimento do público. No decorrer da pesquisa verificou-se a falta de transparência tanto por parte das empresas quanto por parte do poder tributante, no que diz respeito as informações tributárias. Destaca-se que para realizar a presente pesquisa foi necessário recorrer a lei de acesso a informação, cujos dados foram fornecidos de forma nada amistosa para o seu tratamento. Além disso, não foi possível realizar comparações com empresas fechadas por falta de acesso aos dados contábeis.

Nesse aspecto chama-se a atenção para a disparidade de critérios de transparência entre a concessão dos benefícios do auxilio emergencial durante a pandemia do covid-19 e os parcelamentos tributários. Enquanto no primeiro os beneficiados têm os dados publicamente disponibilizados de livre acesso, o segundo é necessário apelar para a força da lei para ter acesso a dados que são de interesse público e deveriam, da mesma forma que o auxílio emergencial, estar disponível para análise e acesso. Destaca-se que, por parte das empresas o argumento de manter o sigilo fiscal não pode se sobrepor ao dever de prestação de contas do uso de recursos públicos.

Nesse contexto, sugere-se, a partir desse estudo, que os novos parcelamentos contenham critérios para adesão que permitam a sociedade a aferir sua efetividade no alcance dos objetivos. Entre esses critérios deve estar a obrigatoriedade de transparência e disponibilização dos dados para acesso público e, com isso, tornar possível estudos que permitam analisar a efetividade dos programas de renegociação de dívidas tributárias com maior volume de dados e informações. Além disso, os processos de parcelamentos fiscais devem inserir condições claras e objetivas, baseadas em dados contábeis e financeiros, que permitam assegurar e aferir o resultado esperado dos programas de renegociação de dívidas tributárias, e de fato atender ao interesse público.

Destaca-se que esta pesquisa se limita à análise do Z-score de insolvência considerando o modelo de Altman. Pesquisas futuras poderiam ampliar as análises utilizando outros modelos de previsão de insolvência e expandir a amostra para empresas fechadas. Além disso, outros critérios, como geração de renda, emprego e investimento social podem ser considerados para a análise da efetividade dos parcelamentos fiscais. Por outro lado, pesquisas futuras podem analisar quais os grupos de interesse exerceram seu poder para pressionar os governantes a instituir os programas de regularização, conforme asseverado pela Teoria da Captura.

\section{REFERÊNCIAS}

Alm, J. (1998). Tax policy analysis: the introduction of a Russian tax amnesty. SSRN Eletronic Journal.

Alm, J. (2018). What motivates tax compliance? Journal of Economic Surveys, 00 (0), 1-36.

Alm, J., Mckee, M, \& Beck, W. (1990). Amazing grace: tax amnesties and compliance. National Tax Journal, $43(1), 23-37$.

Alm, J., Bruner, D. M., \& Mckee, M. (2016). Honesty or dishonesty of taxpayer communications in an enforcement regime. Journal of Economic Psychology, 56 (1), 85-96.

Andrade, J. P., \& Lucena, W. G. L. (2018). Análise de desempenho dos modelos de previsão de insolvência e a implementação das Normas Internacionais de Contabilidade. Revista Ciências Administrativas, 24 (2), 1-14.

Andreoni, J. (1991). The desirability of a permanent tax amnesty. Journal of Public Economics, 45 (1), 143-159. 
Altman, E. I. (1968). Financial ratios, discriminant analysis and the prediction of corporate bankruptcy. Journal of Finance, 23 (1), 589-609.

Altman, E. I., Iwanicz-Drozdowska, M., Laitinen, E. K., \& Suvas, A. (2016). Financial distress prediction in an international context: a review and empirical analysis of Altman's Z-Score Model. Journal of International Financial Management \& Accounting, 28 (2), 131-171.

Brasil, Bolsa, Balcão - B3. (2020). Empresas Listadas. Recuperado em 20 set. 2020, de http://www.b3.com. br/pt_br/produtos-e-servicos/negociacao/renda-variavel/empresas-listadas.htm.

Bayer, R-C., Oberhofer, H., \& Winner, H. (2014). The occurrence of tax amnesties: theory and evidence. Working Papers in Economics and Finance, 6, University of Salzburg, Department of Social Sciences and Economics, Salzburg.

Beaver, W. H. (1998). Financial reporting: an accounting revolution. Estados Unidos: Prentice Hall.

Bezerra, E. S., Lagioia, U. C. T., \& Pereira, M. L. (2019). Indicadores Financeiros, Macroeconômicos e de Governança Corporativa na Previsão de Insolvência em Empresas da B3. Contabilidade, Gestão e Governança, 22 (3), 405-422.

Carvalho, C. J de. (2015). Moral hazard e seleção reversa de fornecedores de trade credit: um survey com firmas não listadas. Anais... In: XVIII Seminários de Administração - Semead.

Chung, K. C., Tan, S. S., \& Holdswoth, D. K. (2008). Insolvency prediction model using multivariate discriminant analysis and artificial neural network for the finance industry in New Zealand. International Journal of Business and Management, 39 (1), 19-28.

Corrêa, M. (2019). Endividamento de empresas com o governo cresceu 84\% em seis anos. OGlobo.com. Publicado em: 14 out. 2019 às 09:42hs. Recuperado em 25 jan. 2020, de https://oglobo.globo.com/economia/endividamento-de-empresas-com-governo-cresceu-84-em-seis-anos-24015835.

Christensen, P. O., Flor, C. R., Lando, D., \& Miltersen, K. R. (2014). Dynamic capital structure with callable debt and debt renegotiations. Journal of Corporate Finance, 29 (1), 644-661.

Dias, S. L da. S. V. (2012). O Crédito tributário e as obrigações fiscais no processo de insolvência. Dissertação de mestrado, Universidade do Minho, Braga, Portugal.

Guimarães, A., \& Moreira, T. B. S. (2008). Previsão de insolvência: um modelo baseado em índices contábeis com utilização da análise discriminante. Revista Economia Contemporânea, 12 (1), 151-178.

Guimarães, M., \& Teixeira, P. (2012). Direito das empresas em dificuldades. Fundação Getúlio Vargas.

Horta, R. A., Alves, F. J dos. S., \& Carvalho, F. A. A de. (2014). Seleção de atributos na previsão de insolvência: aplicação e avaliação usando dados brasileiros recentes. Revista de Administração da Mackenzie, $15(1), 125-151$.

Horta, R. A., Borges, C. C. H., \& Jorge, M. J. (2014). Descontinuidade de empresas brasileiras do setor de consumo cíclico: uma metodologia para balanceamento de base de dados utilizando técnicas de data mining. Revista Ambiente Contábil, 6 (1), 99-121.

Horta, R. A., Borges, C. C., \& Santos, F. A. (2015). Previsão de insolvência no setor de material básico aplicando mineração de dados. Revista Universo Contábil, 11 (3), 43-62.

Koenker, R. (2005). Quantile regression. Cambridge University Press.

Langedijk, S., Nicodème, G., Pagano, A., \& Rossi, A. (2014). Debt bias in corporate taxation and the costs of banking crises in the EU. Taxation Papers, 50 (1).

Lei no 13.496, de 24 de outubro de 2017. Institui o Programa Especial de Regularização Tributária (PERT) na Secretaria da Receita Federal do Brasil e na Procuradoria-Geral da Fazenda Nacional; e altera a Lei no 12.249, de 11 de junho de 2010, e o Decreto no 70.235, de 6 de março de 1972. Diário Oficial [da República Federativa do Brasil], Brasília, DF, 2017. Recuperado em 14 fev. 2020, de http://www.planalto. gov.br/ccivil_03/_Ato2015-2018/2017/Lei/L13496.htm. 
Lennox, C. (1999). Identifying failing companies: a re-evaluation of the logit, probit, and DA approaches. Journal of Economics and Business, 51 (1), 347-364.

Marchese, C., \& Cassone, A. (2000). Tax amnesty as price-discriminating behavior by a monopolistic government. European Journal of Law and Economics, 9 (1), 21-32.

Paes, N. L. (2012). O Parcelamento tributário e seus efeitos sobre o comportamento dos contribuintes. Revista Economia, 13 (2), 345-363.

Pêgas, P. H. (2017). Manual de contabilidade tributária. 9 ed. São Paulo: Atlas.

Pereira, R., \& Luiz, C. (2018). Empresas em recuperação judicial devem R\$ 455 bilhões em impostos. Economia Uol. Publicado em: 30 set. 2018 às 13:00hs. Recuperado em 24 set. 2020, de https://atarde.uol.com. br/economia/noticias/1998338-empresas-em-recuperacao-judicial-devem-r-455-bilhoes-em-impostos.

Plutarco, H. M. (2012). A sonegação e a litigância tributária como forma de financiamento. Economic Analysis of Law Review, 3 (1), 122-147.

Procuradoria-Geral da Fazenda Nacional - PGFN. (2018). Programa Especial de Regularização Tributária do Simples Nacional (PERT/SN). Recuperado em 18 dez. 2018, de http://www.pgfn.fazenda.gov.br/servicos-e-orientacoes/servicos-da-divida-ativa-da-uniao-dau/parcelamentos-1/copy_of_parcelamentos/ programa-especial-de-regularizacao-tributaria-do-simples-nacional-pert-sn.

Ruiz, K de, S., \& Campagnoni, M. (2019). Características das empresas que pedem perdão tributário no Brasil. Anais... In: XVI Congresso USP de Iniciação Científica em Contabilidade.

Santos, P., \& Machado, M. J. (2019). A indisponibilidade dos créditos tributários no processo especial de revitalização. Cadernos de Dereito Actual, 12, 289-303.

Scott, W. R. (2014). Financial accounting theory. 7 ed. Toronto: Pearson.

Segura, L. C., Formigoni, H., \& Grecco, M. C. P. (2012). Um estudo sobre a relação entre adesão das companhias abertas ao REFIS e o seu capital de giro líquido. Advances in Scientific and Applied Accounting, 5 (3), 427-446.

Somavilla, J. L., \& Lobato, P. H. B. (2009). A concessão de anistias e incentivos fiscais e a importância do controle da renúncia de receita pelos tribunais de contas. Revista do Tribunal de Contas do Estado de Minas Gerais, 70 (1).

Takar, T. (2019). Lei confusa e multa alta fazem empresas atrasarem tributos, dizem analistas. Recuperado em 29 jul. 2019, de https://economia.uol.com.br/noticias/redacao/2019/02/25/refis-divida-tributaria-impostos-polemica-governo-empresas.htm.

Zala, C. (2018). Unafisco é citada contra REFIS: 'Bolsonaro quer perdoar dívida rural; rombo é de R\$ 17 bi'. Valor Econômico. Recuperado em 27 fev. 2019, de https://www.valor.com.br/brasil/6034935/bolsonaro-quer-perdoar-divida-rural-rombo-e-de-r-17-bi. 